\title{
What Are the Success Factors for a Partnership with Global Medical Device Companies? Evidence from Korea
}

\author{
Dongwoo Kim ${ }^{1}$, Gyu Ha Ryu ${ }^{1,2}{ }^{\mathbb{D}}$, Kwangsoo Shin ${ }^{3, *}$ and Kyu-Sung Lee ${ }^{1,4,5, *}$ \\ 1 Department of Medical Device Management and Research, SAIHST, Sungkyunkwan University, \\ Seoul 06355, Korea; kimd18@g.skku.edu (D.K.); gyuha.ryu@samsung.com (G.H.R.) \\ 2 Office of Technology Commercialization, Samsung Medical Center, Seoul 06351, Korea \\ 3 Department of Biomedical Convergence, College of Medicine, Chungbuk National University, \\ Cheongju 28644, Korea \\ 4 Department of Urology, Samsung Medical Center, Sungkyunkwan University School of Medicine, \\ Seoul 06351, Korea \\ 5 Biomedical Engineering Research Center, Smart Healthcare Research Institute, Samsung Medical Center, \\ Sungkyunkwan University School of Medicine, Seoul 06351, Korea \\ * Correspondence: sksidea@chungbuk.ac.kr (K.S.); ksleedr@skku.edu (K.-S.L.)
}

Citation: Kim, D.; Ryu, G.H.; Shin, K.; Lee, K.-S. What Are the Success Factors for a Partnership with Global Medical Device Companies? Evidence from Korea. J. Open Innov. Technol. Mark. Complex. 2021, 7, 237. https://doi.org/10.3390/ joitmc7040237

Received: 6 September 2021

Accepted: 22 November 2021

Published: 3 December 2021

Publisher's Note: MDPI stays neutral with regard to jurisdictional claims in published maps and institutional affiliations.

Copyright: () 2021 by the authors. Licensee MDPI, Basel, Switzerland. This article is an open access article distributed under the terms and conditions of the Creative Commons Attribution (CC BY) license (https:// creativecommons.org/licenses/by/ $4.0 /)$.

\begin{abstract}
The medical device industry is uniquely characterized by both resourceful global companies and innovative catching-up companies. The studies by Chatterji have analyzed how large and established medical device companies could better utilize the ideas from innovative groups such as physicians. While the existing literature on the topic of open innovation is enriched, there are few studies on the partnership between larger global medical device companies and smaller catching-up medical device companies. This study focuses on a structured partnership with global medical device companies. To understand how such a deal could be better arranged, this study adopted the Analytic Hierarchy Process (hereafter, AHP) analysis to derive the success factors of such partnership with a focus on the case of the Korean medical device industry. This survey interviewed 30 experienced professionals who currently work for global medical device companies. The study results found that global medical device companies prefer a licensing deal along with broader territories. In terms of the preferred requirements for a partnership deal, the study revealed that there is strong emphasis on factors such as Quality and Intellectual Property (hereafter, IP) protection. This study has practical managerial implications for catching-up medical device companies which drive an open innovation practice with a view to accelerating their growth trajectory in the global market.
\end{abstract}

Keywords: medical device industry; open innovation; analytical hierarchy process; global partnership

\section{Introduction}

To excel in an increasingly competitive market environment, the leading players in the healthcare industry have been transitioning to an open innovation model in recent decades [1]. Multinational pharmaceutical companies are open to this transition as they have to cope with the need to minimize the gap of their own product portfolio by adopting open innovation practices such as licensing [2]. The companies pursue the integration of external resources in an effort to reduce the uncertainty around their pathway to growth $[3,4]$. In this important transition, the medical device industry is not an exception. Large and established global medical device companies spend billions of dollars in their Research \& Development (hereafter, R\&D) projects every year and actively explore outside technologies at the same time [5]. In line with these efforts, strategy scholars argue that innovation lies beyond the boundaries among firms, and this innovation plays a critical role in improving firm performance [6]. With regard to the firm performance improvement, Batternik [7] argued that the pursuit of an open innovation strategy allows companies to perform better. More specifically, Eisenhardt et al. argue that the role of dynamic capabilities in gaining 
resources and the authors explain the superior performance of biotech firms along with the firms' good alliancing processes for external knowledge [8].

While these large medical device companies maintain their dominant status in the industry, it is known that small medical device companies are taking the lead in providing the industry with innovation in the early stages of product development [9]. The open innovation practice of the large players to secure external technologies is categorized as in-bound open innovation through an outside-in process and that of small players to generate revenue by making their technology available to external parties is called outbound open innovation through an inside-out process [10]. The small players equipped with innovation look to better leverage their own technology in out-bound open innovation processes [11]. This type of external technology exploitation allows the small players to commercialize their technology assets [12]. This pursuit of commercialization is also applicable to a firm's IP as the tendency of locking up its IP is relatively low these days [13]. As the originator of the IP does not need to relinquish the ownership of the knowledge, the sharing of knowledge across firms is more widely accepted [14]. This wider acceptance can be explained by the concept of desorptive capacity. Though a firm desorbs its knowledge, the firm's application of the knowledge is not precluded [15].

A substantial amount of scholarly work has examined what drives firms to pursue open innovation by securing external knowledge [1]. When it comes to the pharmaceutical companies, the firms are directly faced with the decreasing productivity of their R\&D projects, and they want to minimize potential risks by seeking collaboration with external parties $[16,17]$. The question of how open innovation can be categorized based on the direction of knowledge transfer was explored in multiple papers. The papers have categorized open innovation as inside-out, outside-in, and coupled [10]. While there are many important prior works on open innovation, there is a lack of specific empirical evidence on open innovation in the medical device industry due to the following reasons. First, it might be the case that the medical device industry was less focused on research on open innovation. Second, there is limited research that attempts to understand the specific success factors for open innovation practices between larger global companies and smaller catching-up companies. Lastly, few studies have explored the specific practices of out-bound open innovation [18].

The objective of this study is to identify the success factors for a partnership between global medical device companies and Korean medical device companies with the use of AHP. Considering the aim of this study, setting priorities was necessary, and the AHP method was selected as an appropriate option [19]. For a better follow-up on the continued efforts of previous studies, this paper aims to explore the prioritized factors which could drive the bilateral interaction between the two parties. As the deal-making of open innovation practices is quite complex and multifaceted, this study took the unprecedented approach of attempting to identify both internal conditions (candidate's readiness) and external conditions (deal terms). To derive the customized categories for each set of analysis, this study conducted an extensive literature review.

The results of this study may contribute to the open innovation strategy of Korean medical device companies when they plan to partner with global medical device companies. First, considering that Korean medical device companies are still catching up with the status of global medical device companies, the managerial recommendations from the study will be helpful for other companies in catching-up countries in the industry [20]. Second, by taking the unique characteristics of the medical device industry into consideration, this paper analyzes both internal and external conditions to pursue a partnership with global medical device companies based on the open innovation approach. Third, the AHP analysis in the study is suited to hierarchically clarify the relative importance of each sub-category for the establishment of partnership guidelines. The remainder of this paper is structured as follows: Section 2 introduces the background and literature review. Section 3 describes the method of this study. Section 4 presents the results from the study, and Section 5 discusses the findings. Lastly, Section 6 concludes this paper. 


\section{Background \& Literature Review}

\subsection{Global Medical Device Industry}

The global medical device industry is highly driven by a few big markets such as the US, Japan, Germany, and China. In 2019, the US had the world's largest medical device market, with the size of $\$ 172.9$ billion [21]. It was followed by three major markets; Japan ( $\$ 28.9$ billion), Germany (\$28.5 billion), and China (\$27.3 billion) [22]. Though the US will maintains its status as the world's largest medical device market, other regions such as Asia Pacific and the EU, will continue their growth at a faster pace over the next few years [9]. With regard to the five-year compound annual growth rate (hereafter, CAGR) from 2014 to 2019, China has the highest CAGR $(9.3 \%)$ and the US has also shown a solid growth, with a CAGR of $5.4 \%$ [23].

The medical device industry is characterized by a unique mixture of both large established companies and thousands of small companies [24]. While the large companies take the lead in terms of revenue, the small companies play a critical role as the source of innovation in the earlier stages of R\&D [9]. There are two reasons why the medical device industry has the important role of the small companies. First, medical devices are a very heterogeneous group of products compared to drugs, regarding aspects such as design, use, and purpose [9]. The fact that there are about 1700 different types of medical devices explains this heterogeneity [9]. Second, the medical device industry has a highly knowledgeable group of users, who are mostly physicians. As the small medical device companies are generally more receptive to change, this characteristic can support the knowledge transfer from users [25]. These users are motivated to learn the unmet needs they have figured out in a hospital setting [26,27]. Thus, the users are in the forefront of product development through their complex interaction with medical device companies [28]. The feedback from users allows medical devices to continue their gradual improvement $[29,30]$. The users also work as the apparent source of innovation and launch a new product along with their smaller start-ups. In other words, the opinions of users allow medical device companies to further innovate [31].

\subsection{Korean Medical Device Industry}

The medical device industry in Korea continues its significant growth but is still faced with several challenges associated with the characteristics of the industry. In 2019, the Korean medical device market was worth $\$ 6.6$ billion and was the ninth largest market in the world [32]. Though its market size is ranked relatively high, the Korean medical device market takes up only a $1.6 \%$ share of the global medical device market [32,33]. On top of the size of the market, the fact that there is no Korean medical device company among the world's leading players also explains why Korea is a catching-up country in terms of the advancement of the medical device industry [12]. While Korea leads the Information Technology (hereafter, IT) industry globally, it is true that the Korean medical device industry is not positioned as a leader in the global market.

The industry is generally characterized by thousands of Small- and Medium-sized Enterprises (hereafter, SMEs) and does not have many companies with global operation. As most medical device companies in Korea are relatively small in their revenue sizes, they tend to lack funding for R\&D investment and clinical trials [34,35]. The fact that Korean medical device companies have limited resources also explains why they have greater needs for open innovation [36]. These characteristics require Korean medical device companies to be motivated to partner with global medical device companies for a necessary market expansion to overseas markets. Such a collaboration allows Korean medical device firms to benefit from the expertise of global medical device companies in the domain of marketing, regulatory affairs, and others [37]. Mathews' argument that resources can not only be built internally but also traded well supports Korean firms' efforts to leverage the capabilities of global firms for overseas market expansion [38]. 


\subsection{Open Innovation in the Medical Device Industry}

The concept of open innovation is no longer foreign to most stakeholders in the medical device industry. Due to the chronic challenges associated with R\&D efficiency, the pharmaceutical industry has already attempted to make a transition to the concept of open innovation in earlier years [16]. This transition has also occurred in the medical device industry in recent years.

As the medical device industry faces a higher level of competition in the market, it has become more critical for medical device companies to secure a competitive advantage which allows them to compete with others for sustained growth. Given the fiercely competitive environment, the Resource-Based View (RBV) is known to provide the firms with an important framework to better understand how a competitive advantage can be achieved and how such an advantage can last in a sustainable manner [8]. Resources that are rare and non-substitutable can play a pivotal role in offering a sustained competitive advantage over others [39]. When it comes to the resources for medical device companies, they include both tangible and intangible resources such as IP, fund, quality certificate, and others. While most medical device companies strive to be equipped with internal capabilities for their sustained growth, some resources can be better obtained from external sources [8]. Researchers have theorized that dynamic capabilities are strategic processes to access external knowledge with the purpose of implementing value-creating strategies [8].

Multiple strategy scholars have underlined the importance of knowledge management processes to better explore or exploit knowledge in pursuing open innovation. The important work of Cohen and Levinthal [40] discussed the absorptive capacity to explain the stage of acquiring external knowledge and assimilating it. As firms are increasingly focusing on interactive knowledge transactions to broaden their knowledge base, scholars began paying attention to the concept of knowledge exploitation [15]. In an effort to build an integrative view of knowledge management in open innovation, Lichtenthaler [15] came up with a framework for managing both internal and external knowledge. The framework proposes six knowledge capacities: incentive capacity, transformative capacity, and innovative capacity are for internal knowledge management and absorptive capacity, connective capacity, and desorptive capacity are for external knowledge management. In the context of open innovation processes, firms which plan an outward knowledge transfer require desorptive capacity and firms which drive the acquisition of knowledge need absorptive capacity $[15,41]$.

One of the most widely recognized open innovation processes has the following archetypes: outside-in, inside-out, and coupled [10]. Among the three archetypes, outsidein has been playing a key role in helping large medical device companies to diversify their sources of knowledge. The criticality of external knowledge to the innovation process supports the role of outside-in practice [40]. Multiple papers on open innovation have also proved that outside-in processes are the most popular choices by firms [42].

In the past, large medical device companies have relied on internal R\&D projects to build their product portfolios [43]. Their key technological knowledge was mostly developed in-house [11,43]. Based on the argument of Lichtenthaler [12], this traditional approach belongs to the category of closed innovators with limited external technology. While the large medical device companies continue to focus on internal product development, they are also leveraging external partnerships and M\&As as a tool to further bet on bolder innovation [2]. M\&As allow these companies to diversify their technological portfolio a lot faster than their internal development [44]. Mikus et al. [45] also argued that companies can pursue their own R\&D projects, but there are occasions when they do not have the knowledge and the technology which they need. The fact that the acquisition of new knowledge and technology from external parties was proven to be a more efficient approach also supports this transition [45]. This change in their innovation strategy is tightly related to the current challenges which they are faced with: the pressure to both improve efficiency and reduce costs in an effort to cope with the ever more competitive market 
environment [43]. In addition, the ever-shorter product life cycles caused by competition require a faster development cycle-time by exploiting external sources [46].

Small medical device companies which are generally equipped with unique technological strengths pay more attention to inside-out open innovation opportunities. As the medical device industry is more technology-centric than before, these technological strengths enable the small medical device companies to attempt to execute the inside-out open innovation strategy more actively [47]. In these inside-out processes, companies exploit their own knowledge by taking ideas to the market or selling IP [42]. A common example of this strategy is a technology licensing agreement aiming at additional revenue [11]. By this type of licensing agreement, the companies attempt to generate more revenue and achieve the strategic direction of actively commercializing knowledge [12].

The open innovation strategies which allow the companies to execute external collaborations include M\&As, joint ventures, joint research, and partnerships [11].

\subsection{Research Framework and Variables}

To derive the main criteria for each AHP analysis, this study conducted a literature review. While previous studies took the fragmentary approach to the success factors of partnership, this study pursues a comprehensive approach by taking both internal conditions and external conditions into consideration. The main criteria of internal conditions are (1) regulatory readiness, (2) quality readiness, (3) funding status, and (4) IP readiness.

First, as an increasing number of medical device companies are exploring the regulatory approval of products in multiple jurisdictions and the process is a critical pathway in the medical device development, regulatory approval works as a critical factor for the readiness assessment $[5,37,48]$. The fundamental nature of a partnership deal with a global medical device company requires a certificate in each target country [9]. A survey with R\&D leaders at leading medical device companies also confirmed that $95 \%$ of respondents identified global regulatory requirements as a top challenge in the coming years [43]. In line with the four largest medical device markets (the US, Japan, Germany, and China), this research came up with three sub-categories: Food and Drug Administration (hereafter, FDA), CE (Conformité Européenne, hereafter CE), and National Medical Products Administration (hereafter, NMPA)/Pharmaceuticals and Medical Devices Agency (hereafter, PMDA) [23]. Then, the Ministry of Food and Drug Safety (hereafter, MFDS) for Korea was added as it is a certificate for most Korean medical device companies.

Second, while obtaining regulatory approval is a key task in the medical device development, establishing a quality system is also important as a medical device can have a direct impact on the health of a patient $[49,50]$. Due to this importance, the production and use of a medical device is firmly regulated by both local laws and international certificate systems [9]. As Korean Good Manufacturing Practice (hereafter, KGMP) is a mandatory certificate for any product to be sold in Korea, the certificate is selected as a subcategory for the quality readiness category [51]. International Standard Organization 13485 (hereafter, ISO 13485) is a well-established Quality Management System standard for the medical device industry [52]. Most medical device companies which plan to enter overseas markets are advised to be equipped with ISO 13485. In an effort to seek consistency among regulatory bodies across the world, the Medical Device Single Audit Program (hereafter, MDSAP) was implemented by an alliance of five regulatory partners (Australia, Brazil, Canada, Japan, and the US). As the program meets the regulatory needs of the participating countries, it can significantly reduce the burden of multiple inspections by producing a harmonized single audit [32]. Lastly, the sub-category of cyber-security is selected due to the increasing emphasis on the prevention of cyber-attacks against connected medical devices, especially against personal medical devices [53].

Third, Lee [54,55] argued that one of the success factors for medical device start-ups is funding (funding capacity and available funds), and this selection is also aligned with the fact that the medical device industry is quite R\&D-intensive, along with the needs for investment [24]. As firm size and age have an influence on a firm's knowledge strategies, it is 
meaningful to have sub-categories which can represent each funding stage [47]. The earliest funding stage begins with angel financing by business angels [56]. Then, multiple rounds of funding will generally follow, and this study came up with the following sub-categories: Angel/seed, Series A, Series B, and Series C/Initial Public Offering (hereafter, IPO).

Fourth, in the highly R\&D-intensive medical device industry, patents play an important role in a firm's innovation capabilities [24,57]. Patents enable a firm to maintain technological advantages and work as the appropriate indicator of different innovation capabilities [11]. In addition, the R\&D staff finds the existence of patents quite important as the process works as a pre-requisite to pursue further product development $[58,59]$. The development of medical devices requires the review of the IP landscape, and the pursuit of the specific development project can be determined based on the results of a risk management capability assessment [50]. The internal policy of global medical device companies also requires a potential partner to be equipped with a patent to prevent any latent allegation [60]. The filing of a local patent is an initial step for intellectual property management, and the Korean Intellectual Property Office (hereafter, KIPO) grants a local patent if a specific technology meets all the requirements [61]. The Patent Cooperation Treaty (hereafter, PCT), an efficient solution for acquiring patent protection in most member countries, is widely selected by local medical device companies [59,62]. This system serves as the tool for entry barriers in the overseas markets [63]. The PCT helps a device company to protect its information through a lead time over potential competitors [64]. While the processes of filing and granting are highly interrelated, this paper separated the two stages as it takes at least multiple months to move from the status of filed patent to the status of granted patent. In accordance with the local and international patent system, this research could have the following sub-categories: Local Patent Filed, Local Patent Granted, PCT Filed, and Overseas Patent Granted.

Hence, the research derived the following criteria for the internal conditions (candidate's readiness) analysis: regulatory readiness, quality readiness, funding status, and intellectual property readiness (Figure 1).

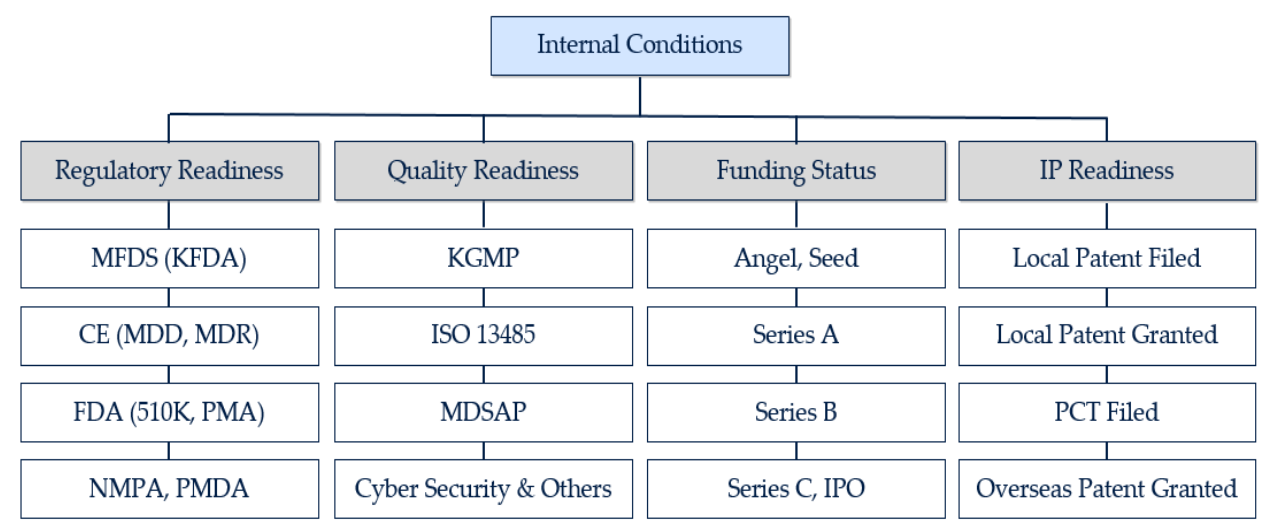

Figure 1. Research framework: internal readiness for partnership.

An AHP analysis of external conditions is used to understand what type of deal structure is preferred by global medical device companies. While the internal conditions (candidate's readiness) focus on the requirements, the external conditions lay out prioritized criteria which could have a major impact on a partnership agreement. The main criteria of external conditions are (1) type of partnership, (2) targeted geography, (3) choice of brand, and (4) investment type.

First, in line with the objective of the analysis for external conditions, the question of which type of partnership to pursue is one of the main criteria for this analysis. The common practices of open innovation include outsourcing, M\&A, and others [65]. Contract manufacturing lets a partner company manufacture a global medical device company's product, and it is an apparent case of outsourcing [66]. Lichtenthaler [67] stressed the increasing trend of the external exploitation of knowledge, and a licensing deal was one 
of the options. While a licensing deal aims at utilizing the R\&D capabilities of a potential partner through a contractual arrangement, a distribution deal focuses directly on the sales and marketing of a certain product [68]. In case of a distribution deal, a global medical device company works as a distributor for certain geographies. Mergers and Acquisitions (hereafter, M\&A) pursues the full control of a partner company along with the significant amount of capital investment. Despite the need for the investment, larger firms are motivated to acquire a full entity as the key capabilities which are embedded in a target can be better obtained [69]. Thus, the following sub-categories are derived in the type of partnership category: contract manufacturing, distribution deal, licensing deal, and M\&A.

Second, considering that this study covers a partnerships with global medical device companies, which geography to target is an important consideration factor to be discussed. Most licensing contracts define the territory for a deal, and the choice of a cross-border deal is not uncommon [70]. This factor is known to be critical for a global medical device company, as the choice of market relates to its registration strategy and marketing plan. On top of the home market (Korea), the largest targetable geography is added: the global market. Then, based on both the maturity of a market and the level of technology to be preferred, the emerging market (including China) and developed market (including the US and EU) are derived. The emerging market sub-category includes countries such as Brazil, India, Russia, Indonesia, and China [71]. The average growth rates of those markets are well above those of developed markets. The EU, a trading bloc, remains the largest importer of US medical devices and is a clear representative of the developed market along with the US [21]. Hence, the selected sub-categories are Korea, emerging market, developed market, and global (market).

Third, brand is another major factor in external conditions as it has a direct association with regulatory approval and product reputation [72]. As the contractual arrangement of the Original Equipment Manufacturer (hereafter, OEM) is perceived as a favorable tool for a firm's business expansion, the brand of a global medical device company is one of the preferred choices in a partnership deal [73]. While the choice of Multinational Corporation (hereafter, MNC) brand remains as a common option, the increasing emphasis on the brand equity of an individual firm makes a manufacturer become more interested in the choice of its own brand. In this study, the choice of a manufacturer's own brand will be called partner brand as it explores the possibility of partnering with a global medical device company. While these two choices are relatively common, this study also paid attention to two emerging choices: revised brand and new brand. Revised brand is a hybrid choice as it is based on the brand of a manufacturer but has the flavor of a global medical device company along with any symbol or word representing the global company. New brand refers to a case when a whole new brand is created for a specific partnership deal. The sub-categories in the brand category are as follows: partner brand, MNC Brand, revised brand, and new brand.

Some open innovation strategies, such as M\&A and technology acquisition, require monetary investment, but for others, such as distribution agreement, monetary investment is optional [35,74]. The type of investment mainly defines the timing of an investment and is a critical decision item for any global medical device company, given its nature as a listed company (in most cases). While a non-investment deal is known as the lightest choice for any company, some companies do consider investment options such as early-stage investment or minority equity investment. Early-stage investment is generally considered when a target company needs to improve its quality standard or be equipped with an additional manufacturing facility. Minority equity investment is executed when a global medical device company finds a deal quite successful and wants to support the capacity expansion of a target company. While minority equity investment by a Private Equity (hereafter, PE) firm generally focuses on a firm performance improvement, global medical device companies focus on how such an investment could support the specific partnership deal [75]. M\&A is a preferred choice, but it is also true that such an investment is considered when the level of certainty is meaningfully high [13]. Consequently, the following sub- 
categories are derived: non-investment deal, early-stage investment, minority equity investment, and acquisition.

Therefore, the following criteria for the external conditions are obtained: type of partnership, targeted geography, brand, and type of investment (Figure 2).

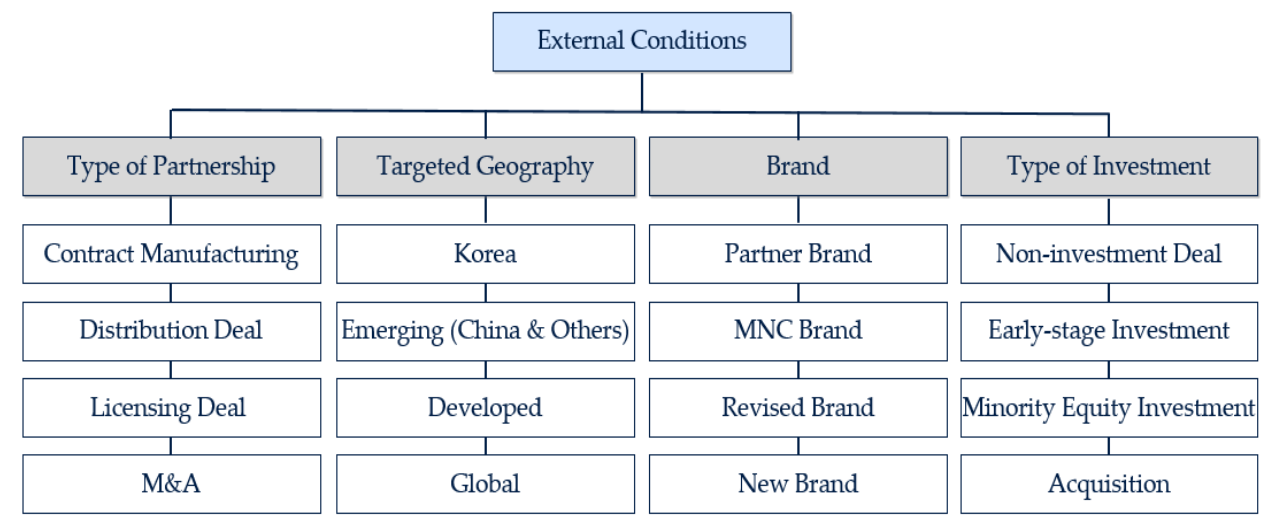

Figure 2. Research framework: external conditions for partnership.

\section{Methodology}

\subsection{Data}

This study interviewed a total of 30 experienced professionals from global medical device companies such as Medtronic, Johnson \& Johnson, Stryker, Roche, Canon, and Alcon. Regarding the total number of years in the healthcare industry, the group of 15-20 years was found to be the largest one, and the group of 10-15 years was the second largest. As there is a tight correlation between age and work experiences, $40 \mathrm{~s}(50 \%)$ was the largest age group, and 30s (26.7\%) was the second largest. In terms of function (expertise), QA/RA (33.3\%) was found to be the largest one, and both Marketing (20\%) and Business Development $(20 \%)$ were the second largest ones. There was an even distribution between Male (50.0\%) and Female (50.0\%). More detailed results are shown below (Table 1).

\subsection{Analytic Method}

In alignment with the objective of the research, this study conducted an AHP analysis to identify the success factors for a partnership between Korean and global medical device companies. As this study aims at identifying the success factors from both internal conditions (candidate's readiness) and external conditions (deal terms), it ran two sets of AHP analysis. This method focuses on prioritizing multiple criteria by conducting a pairwise comparison of the importance of each criterion [19]. It allows a decision maker to have a structured view on a certain situation by choosing the factors which are more important [76]. The AHP analysis is helpful for tackling this complex issue of partnering between medical device companies [54].

The survey respondents mainly include experienced professionals from global medical device companies across the globe. In terms of their employers, this study wanted to make sure that they belong to diverse product areas such as surgical instruments, diagnostics imaging, and orthopedics. While this research began by interviewing commercial teams such as Sales and Marketing, the research also secured the interviews with diverse functions including Quality Assurance (hereafter, QA), Regulatory Affairs (hereafter, RA), Reimbursement, Clinical, Sourcing, and Business Development. This survey was conducted from 10 May 2021 to 25 June 2021. 
Table 1. Survey respondent demographics.

\begin{tabular}{ccc}
\hline Demographics & Frequency & Percentage \\
\hline Gender & 15 & 50.0 \\
Male & 15 & 50.0 \\
Female & & \\
Age & 2 & 6.7 \\
$20 \mathrm{~s}$ & 8 & 26.7 \\
$30 \mathrm{~s}$ & 15 & 50.0 \\
$40 \mathrm{~s}$ & 5 & 16.7 \\
$50 \mathrm{~s}$ & & \\
Work Experiences & 2 & 9.5 \\
$0 \sim 5$ years & 3 & 14.3 \\
$5 \sim 10$ years & 7 & 33.3 \\
$10 \sim 15$ years & 12 & 57.1 \\
15 20 years & 6 & 28.6 \\
20 years & & \\
Expertise (Function) & 5 & 16.7 \\
QA & 5 & 16.7 \\
RA & 3 & 10.0 \\
Clinical & 4 & 13.3 \\
Reimbursement & 6 & 20.0 \\
Marketing & 6 & 20.0 \\
Business Development & 1 & 3.3 \\
Sourcing & &
\end{tabular}

\section{Results}

This study conducted the two sets of AHP analysis: internal conditions and external conditions. The former is to understand the requirements for Korean medical device companies and the latter is to understand the preferred deal conditions by global medical device companies. The pairwise comparison of the sub-categories allowed this study to identify both the priority and the importance of each sub-category.

The comprehensive analysis (Table 2) to understand the integrated perspectives for classifying the importance of both internal and external conditions shows that $60 \%$ out of the top 5 sub-categories belong to external conditions. In terms of the sub-category with the highest importance, ISO 13485 (Quality) is found to have the importance of 0.270 . The analysis for the top 10 sub-categories shows that there is a good balance between internal and external conditions as both conditions take up 50\% of the sub-categories, respectively. With respect to the sub-categories in the top 50\% percentile, both internal and external conditions occupy 50\% each. Another analysis for the sub-categories in the top 50\% percentile found that both Quality (internal) and Partnership (external) have high overall importance, as each criterion has all four sub-categories in the top $50 \%$.

With respect to the internal conditions (candidate's readiness), the results present that global medical device companies have a distinct preference for the category of quality. Three quality-related sub-categories (ISO 13485, MDSAP, and KGMP) are on the top 5 in Table 3. The sub-categories of FDA and CE are ranked fifth and sixth, and these priorities explain the importance of regulatory readiness to the global device companies. While overseas patent granted has the second highest importance (0.089), other sub-categories of both IP and funding are relatively less importance. 
Table 2. Results of internal and external conditions.

\begin{tabular}{|c|c|c|}
\hline Item & Priority & Importance \\
\hline ISO 13485 (Quality) & 1 & 0.270 \\
\hline Global (Geography) & 2 & 0.217 \\
\hline Licensing Deal (Partnership) & 3 & 0.118 \\
\hline Distribution Deal (Partnership) & 4 & 0.116 \\
\hline Overseas Patent Granted (IP) & 5 & 0.089 \\
\hline Developed (Geography) & 6 & 0.089 \\
\hline Contract Manufacturing (Partnership) & 7 & 0.071 \\
\hline MDSAP (Quality) & 8 & 0.069 \\
\hline KGMP (Quality) & 8 & 0.069 \\
\hline FDA (Regulatory) & 10 & 0.067 \\
\hline Emerging (Geography) & 11 & 0.063 \\
\hline M\&A (Partnership) & 12 & 0.061 \\
\hline CE (Regulatory) & 13 & 0.057 \\
\hline Series C (Funding) & 14 & 0.053 \\
\hline Cyber Security (Quality) & 15 & 0.051 \\
\hline MNC (Brand) & 16 & 0.043 \\
\hline Korea (Geography) & 17 & 0.040 \\
\hline Revised (Brand) & 18 & 0.040 \\
\hline Minority Investment (Investment) & 19 & 0.032 \\
\hline Acquisition (Investment) & 20 & 0.027 \\
\hline Local Patent Granted (IP) & 21 & 0.027 \\
\hline PCT Filed (IP) & 22 & 0.026 \\
\hline Non-Investment (Investment) & 23 & 0.025 \\
\hline Partner (Brand) & 24 & 0.025 \\
\hline Series B (Funding) & 25 & 0.021 \\
\hline MFDS (Regulatory) & 26 & 0.020 \\
\hline Early-Stage Investment (Investment) & 27 & 0.019 \\
\hline New (Brand) & 28 & 0.013 \\
\hline Series A (Funding) & 28 & 0.013 \\
\hline Angel (Funding) & 30 & 0.012 \\
\hline NMPA/PMDA (Regulatory) & 31 & 0.012 \\
\hline Local Patent Filed (IP) & 32 & 0.006 \\
\hline
\end{tabular}

Table 3. Results of internal conditions (candidate's readiness).

\begin{tabular}{ccc}
\hline Item & Priority & Importance \\
\hline ISO 13485 (Quality) & 1 & 0.270 \\
Overseas Patent Granted (IP) & 2 & 0.089 \\
MDSAP (Quality) & 3 & 0.069 \\
KGMP (Quality) & 4 & 0.069 \\
FDA (Regulatory) & 5 & 0.067 \\
CE (Regulatory) & 6 & 0.057 \\
Series C (Funding) & 7 & 0.053 \\
Cyber Security (Quality) & 8 & 0.051 \\
Local Patent Granted (IP) & 9 & 0.027 \\
PCT Filed (IP) & 10 & 0.026 \\
Series B (Funding) & 11 & 0.021 \\
MFDS (Regulatory) & 12 & 0.020 \\
Series A (Funding) & 13 & 0.013 \\
Angel (Funding) & 14 & 0.012 \\
NMPA/PMDA (Regulatory) & 15 & 0.012 \\
Local Patent Filed (IP) & 16 & 0.006 \\
\hline
\end{tabular}

The analysis of regulatory readiness confirmed that FDA has the highest priority along with the importance of 0.067 . CE has the second highest priority (importance: 0.057 ) and was followed by MFDS (Korea), with the importance of 0.020 . While NMPA (China) and 
PMDA (Japan) are still important approvals, they were regarded as less critical approvals (importance: 0.012) compared to FDA and CE (Table 4).

Table 4. Results of regulatory readiness.

\begin{tabular}{ccc}
\hline Item & Priority & Importance \\
\hline FDA (Regulatory) & 1 & 0.067 \\
CE (Regulatory) & 2 & 0.057 \\
MFDS (Regulatory) & 3 & 0.020 \\
NMPA, PMDA (Regulatory) & 4 & 0.012 \\
\hline
\end{tabular}

Quality readiness is one of the most important success factors when a global medical device company evaluates the readiness of a Korean medical device company. ISO13485 was confirmed as the highest priority sub-category (importance: 0.270 ). MDSAP was found to have the second highest priority (importance: 0.069 ) and was followed by KGMP with a very small gap (Table 5).

Table 5. Results of quality readiness.

\begin{tabular}{ccc}
\hline Item & Priority & Importance \\
\hline ISO 13485 (Quality) & 1 & 0.270 \\
MDSAP (Quality) & 2 & 0.069 \\
KGMP (Quality) & 3 & 0.069 \\
Cyber Security (Quality) & 4 & 0.051 \\
\hline
\end{tabular}

The sub-category of ISO13485 (priority: 1, importance: 0.270 ) is ranked first among all the 16 sub-categories for internal conditions, and other sub-categories of MDSAP and KGMP are ranked third and fourth, respectively. This strong emphasis on quality reaffirms the direct impact of medical devices on the health of a patient $[50,51]$. With respect to MDSAP, the result could derive from the following supporting factors. First, as Chatterij [24] pointed out, medical devices have a relatively shorter product life cycle, so it is critical to save time to obtain the required overseas certificates by leveraging this type of simplified process. Medina et al. [77] also stated that the global market continues its competition on a time basis. Second, the fact that the total market share of the five member countries (the US, Japan, Canada, Australia, and Brazil) exceeds 50\% of the global medical device market provides support for the high preference by the global medical device companies [21]. In addition, the fact that a global medical device company is generally responsible for a potential product safety issue as a distributor also explains why those companies consider quality as a top priority [9].

Among the sub-categories of funding status, Series $\mathrm{C}$ clearly has the highest priority with the importance of 0.053 (Table 6). The study results find that global medical device companies apparently prefer well-funded/mature companies as funding allows a company to be better prepared for most requirements for a global partnership.

Table 6. Results of funding status.

\begin{tabular}{lll}
\hline \multicolumn{1}{c}{ Item } & Priority & \multicolumn{2}{c}{ Importance } \\
\hline Series C (Funding) & 1 & 0.053 \\
Series B (Funding) & 2 & 0.021 \\
Series A (Funding) & 3 & 0.013 \\
Angel/Seed (Funding) & 4 & 0.012 \\
\hline
\end{tabular}

Lee [54] argued that funding is an important success factor for medical device startups, and this result is consistent with the argument. In the category of funding status, the results found that there is an apparent preference for mature start-ups in the funding stage 
of either series B or series $C$. This preference confirms that the medical device $R \& D$ and its commercialization require constant investment [34].

The analysis of IP readiness found that an overseas-focused patent strategy along with PCT has the higher priority over a local patent. Overseas patent granted has the highest priority (priority: 1 , importance: 0.089 ) and was followed by local patent granted, with the importance of 0.027 (Table 7).

Table 7. Results of intellectual property readiness.

\begin{tabular}{llc}
\hline \multicolumn{1}{c}{ Item } & Priority & Importance \\
\hline Overseas Patent Granted (IP) & 1 & 0.089 \\
Local Patent Granted (IP) & 2 & 0.027 \\
PCT Filed (IP) & 3 & 0.023 \\
Local Patent Filed (IP) & 4 & 0.006 \\
\hline
\end{tabular}

Overseas patent granted (importance: 0.089 ) is found to have the second highest importance among all the sub-categories, and this result is well aligned with the increasing importance of IP in the R\&D-intensive medical device industry [71]. Davis [57] stated that MNCs require a comprehensive intellectual property rights protection from the beginning due to their global partnership, and the result of this study is consistent with this view. With respect to the overall importance of IP, Kim et al. [1] opined that patenting becomes a primary factor in a firm's innovation process.

These external condition results show that global medical device companies put an emphasis on two categories: targeted geography and type of partnership. Out of the seven sub-categories with high priorities, four are about type of partnership (licensing deal, distribution deal, contract manufacturing, and M\&A) and three (global, developed, and emerging) are about targeted geography. As this external condition analysis has the aim of understanding more important deal terms when it comes to a global partnership discussion, the results show that global medical device companies found both geography and partnership type fundamental. The categories of brand and investment are placed relatively lower in Table 8.

Table 8. Results of external conditions (deal terms).

\begin{tabular}{lcc}
\hline \multicolumn{1}{c}{ Item } & Priority & Importance \\
\hline Global (Geography) & 1 & 0.217 \\
Licensing Deal (Partnership) & 2 & 0.118 \\
Distribution Deal (Partnership) & 3 & 0.116 \\
Developed (Geography) & 4 & 0.089 \\
Contract Manufacturing (Partnership) & 5 & 0.071 \\
Emerging (Geography) & 6 & 0.063 \\
M\&A (Partnership) & 7 & 0.061 \\
MNC (Brand) & 8 & 0.043 \\
Korea (Geography) & 9 & 0.040 \\
Revised (Brand) & 10 & 0.040 \\
Minority Investment (Investment) & 11 & 0.032 \\
Acquisition (Investment) & 12 & 0.027 \\
Non-Investment (Investment) & 13 & 0.025 \\
Partner (Brand) & 14 & 0.025 \\
Early-Stage Investment (Investment) & 15 & 0.019 \\
New (Brand) & 16 & 0.013 \\
\hline
\end{tabular}


In terms of partnership type, licensing deal (importance: 0.118) and distribution deal (importance: 0.116) have higher priorities than contract manufacturing (importance: 0.071) and M\&A (importance: 0.061) (Table 9). Though M\&A is a preferred choice for global medical device companies, the interviewees generally put more emphasis on the lighter choices as those choices are more feasible.

Table 9. Results of partnership type.

\begin{tabular}{lccc}
\hline \multicolumn{1}{c}{ Item } & Priority & \multicolumn{2}{c}{ Importance } \\
\hline Licensing Deal (Partnership) & 1 & 0.118 \\
Distribution Deal (Partnership) & 2 & 0.116 \\
Contract Manufacturing (Partnership) & 3 & 0.071 \\
M\&A (Partnership) & 4 & 0.061 \\
\hline
\end{tabular}

Yun et al. [78] pointed out that the combination of technologies and markets is becoming an emerging trend, and this view is well aligned with open innovation activities such as M\&As, collaborative activities, and outsourcing to reduce costs and increase productivity. The finding from this analysis also supports the view that the sub-categories such as licensing deal and distribution deal have a relatively high importance (of 0.118 and 0.116 , respectively). In line with the view of Kim et al. [65] that licensing agreement is a commonly observed type of inter-firm alliances, licensing deal is found to be the sub-category with the highest preference (priority: 1, importance: 0.118 ) in this analysis. While Lin et al. [60] opined that M\&A is an important tool to strengthen a firm's competencies, this study found that the sub-category of M\&A has a relatively lower importance [priority: 4, importance: 0.061]. Another major finding is the preference for acquiring external technologies [11,37]. Though the gap is not significantly large, there was higher preference for a licensing deal compared to a distribution deal which does not require technology absorption. This finding is supported by the study of Lichtenthaler [40] in that the larger medical device companies are better equipped with absorptive capacity thanks to accumulated experiences from past deals. The argument of Cohen and Levinthal also stressed the importance of prior related knowledge which lets a firm assimilate new information better [40,79].

When it comes to targeted geography, global medical device companies present a quite stronger preference for the larger markets, such as the global and developed ones. Global has the highest priority, with the importance of 0.217 , and is followed by developed (priority: 2, importance: 0.089) (Table 10).

Table 10. Results of targeted geography.

\begin{tabular}{ccc}
\hline Item & Priority & Importance \\
\hline Global (Geography) & 1 & 0.217 \\
Developed (Geography) & 2 & 0.089 \\
Emerging (Geography) & 3 & 0.063 \\
Korea (Geography) & 4 & 0.040 \\
\hline
\end{tabular}

The results of this study indicate that global medical device companies find larger markets more favorable mainly due to the size of the addressable revenue in each market [23]. There is an apparent preference for the sub-category of global (priority: 1, importance: 0.217 ) as global means the entire medical device market in the world. The sub-category with the second highest importance is developed (priority: 2, importance: 0.089) as the developed market with the combination of both the US and the EU represents more than $60 \%$ of the global medical device market [23]. Maresova [9] stated that the Asia Pacific market is expected to expand at a faster pace than that of the US market, and this view explains the meaningfully high importance of the sub-category of emerging (priority: 3 , importance: 0.063 ). 
The analysis of the choice of brand found that the brand of global medical device company was strongly preferred with the importance of 0.043 (Table 11). Revised brand has the second highest priority (importance: 0.402 ) as global medical device companies believe that it is important to keep the brand identity of their own brand.

Table 11. Results of brand.

\begin{tabular}{ccc}
\hline Item & Priority & Importance \\
\hline MNC (Brand) & 1 & 0.043 \\
Revised (Brand) & 2 & 0.040 \\
Partner (Brand) & 3 & 0.025 \\
New (Brand) & 4 & 0.013 \\
\hline
\end{tabular}

With respect to the result of brand choice, the fact that there is a positive correlation between brand image and the purchasing intent of a medical device supports the relatively high preference for MNC brand and revised brand [19]. As the awareness level of the brands of Korean medical device companies is lower than that of global medical device companies, the higher importance of MNC brand (priority: 1, importance: 0.043 ) is identified [19].

In the Investment type category, the results show that global medical device companies prefer to take an achievement-based approach as minority equity investment has the highest priority (importance: 0.032) (Table 12). Early-stage investment has the lowest priority (importance: 0.019 ) as the option was found to be riskier. If a global medical device company is firm on the attractiveness of a candidate, it rather prefers an acquisition (importance: 0.027).

Table 12. Results of investment type.

\begin{tabular}{ccc}
\hline Item & Priority & Importance \\
\hline Minority Equity (Investment) & 1 & 0.032 \\
Acquisition (Investment) & 2 & 0.027 \\
Non-Investment (Investment) & 3 & 0.025 \\
Early-Stage Investment & 4 & 0.019 \\
$\quad$ (Investment) & & \\
\hline
\end{tabular}

While milestone payment in a licensing deal in the pharmaceutical industry is specifically related to the developmental phase of a drug, the equity investment in the medical device industry is supposed to provide a partner company with resources (e.g., funds for capacity expansion) to execute a deal in a more stable manner [65]. Cwalina et al. [80] stated that firms are often faced with difficulties related to regulatory approval and funding while they are translating new ideas into the commercialization phase, and this view supports the importance of minority equity investment in a global partnership deal. Acquisition (priority: 2, importance: 0.027 ) is the second most important sub-category in the investment type analysis, and this result indicates that global medical device companies find the option attractive. The argument that M\&A allows a firm to have more dominance and control also supports the finding of this analysis [63].

\section{Discussion}

The analytical results of this study for open innovation provide a systematic overview of the success factors for a partnership with global medical device companies. Though scholars have already made significant strides in understanding the open innovation in the medical device industry, the results of this study make a few meaningful contributions to prior work on the partnership with global medical device companies by detailing both internal and external conditions. 
First, it needs to be emphasized that global medical device companies have a clear preference for more global and universal standards for open innovation. This preference for a more global standard is explained by the relatively high importance of both FDA and CE in the study. Kampfrath [81] provides a rationale for this strong emphasis on FDA as it is the regulatory agency for the world's largest medical device market. The high importance of $\mathrm{CE}$ among the sub-categories also results from the fact that the EU is the world's second largest medical device market as a region with 27 member countries [21]. Maresova et al. [9] stated that the CE marking certificate proves that a device meets all the regulatory requirements to be sold in the European Union (hereafter, EU). An approval from one of the designated notified bodies allows for marketing activities in any member state [82]. This flexibility of $\mathrm{CE}$ enables medical device companies to better utilize their regulatory-related capabilities. Though the Chinese and Japanese markets take up a relatively large portion of the global market, the approval for each market was not found to be critical as each one of them is solely for one country. The relatively higher importance of the two quality-related international standards (ISO 13485 and MDSAP) also explains that more universal certificates are preferred by the global medical device companies. In addition, the strong emphasis on the international patent supports the notion that global medical device companies prefer a more universal standard. As global medical device companies are seeking market entry in multiple geographies, it is necessary for them to focus on the granted patents at an international level to protect themselves from the emergence of any potential copycat product [43]. This finding is consistent with the view of Lee [19] that it is important to deal with global certificates which require stricter processes for global market entry.

Second, this study's finding suggests that global medical device companies prefer broader territories when they drive outside-in open innovation processes. The results point to the fact that global medical device firms strive to improve efficiency by actively targeting markets with more revenue potential [43]. The estimated size of the global medical device market is $\$ 446$ billion in 2021 , and the size of the addressable revenue clearly supports the strong preference for the global market by the large firms [19]. A significant preference for the choice of developed markets is solidly backed by the fact that three (the US, Japan, and Germany) out of the four largest medical device markets in the world belong to the category of developed markets [22]. This result is consistent with the findings of Lichtenthaler [12] that large firms have abundant resources to drive open innovation processes as the market entry to the developed markets certainly asks for a sizable investment. In line with the view of Cohen and Levinthal [40], the global companies are more likely to have accumulated experiences from the past deals in the US and the EU, and the absorptive capacity allows the companies to target the developed markets in a more manageable manner.

Third, this study provides evidence that global medical device companies want to minimize uncertainty while they approach their open innovation processes. The result of this study shows that the global medical device companies have a preference for more mature firms in terms of funding stage though Gopalakrishnan and Bierly [47] opined that smaller organizations are better suited to innovate thanks to their being more nimble and adaptive. One explanation for this result is that start-ups in the early funding stage may have difficulty in being equipped with key requirements in terms of regulatory approval and quality certificates. The findings from partnership type also explain this avoidance of uncertainty. Though multiple strategy scholars argued for the importance of M\&A as an effective tool to acquire external resources, the results from this study showed a relatively lower preference for M\&A. A follow-up interview to better verify this unique finding showed that global medical device companies find that an M\&A deal with a Korean medical device company is a less feasible choice mainly due to the lack of maturity in terms of technological strengths. While acquisitions can be motivated by multiple factors such as an access to distribution channels and an entry into new markets, the technology-centric characteristic of the medical device industry lets an acquirer become more motivated by the technological capabilities of a target [83]. 


\section{Conclusions}

This study contributes to open innovation literature by examining the success factors for a partnership with global medical device companies based on two main dimensions: (1) internal conditions as firm resources for a competitive position in partnership discussions; (2) external conditions as strategic processes to bring the external resources from global companies. Though multiple authors have explored the topic of open innovation in the medical device industry, the need to provide implications on the partnership with global medical device companies still exists. This empirical analysis of global partnership is, to our knowledge, the first empirical research which attempts to understand how medical device companies in catching-up countries can partner with global medical device companies.

The AHP analysis in this study brings in valuable insights by interviewing 30 experienced professionals in the leading medical device firms. The results of the analysis show that global medical device companies find quality to be the most important factor when evaluating a potential partner, and granted patents for overseas markets are also identified as a critical factor. With respect to external conditions, this analysis confirms that the global medical device firms prefer a licensing deal under their own brands while focusing on larger geographies such as the US and EU markets. In addition to the theoretical contribution, the findings from the study provide several practical implications for Korean medical device companies which pursue a global partnership for overseas market expansion.

First, medical device companies which plan to partner with global medical device companies need to focus on key requirements in terms of both overseas quality certificates and regulatory approvals. With respect to the quality certificates, being equipped with ISO 13485 should be the first focus. As an emphasis on MDSAP is also growing, any medical device firm planning to enter one or more of the member countries for MDSAP is advised to fully leverage the single audit program. While Korean medical device companies have a willingness to enter major markets, including China and Japan, the finding from this analysis suggests that it is more important to be prepared for FDA and CE due to their universal credibility across the global markets. A relevant recommendation for medical device firms in catching-up countries (in the similar context of Korea) is that they should train and educate their quality teams as the function can hardly be outsourced.

Second, medical device firms should build a more customized global partnership strategy in terms of both geography and brand to leverage the preferred deal terms of the global medical device companies. This research shows that global medical device companies have a meaningful preference for a broader target geography with bigger revenue potential and are willing to maintain their own brands. This finding suggests that medical device firms need to focus on a global partnership deal instead of signing multiple regional deals with distributors if they are firm on a partnership with a global medical device firm. When it comes to the choice of brand, Korean medical device companies are better off proposing a revised brand as it is an alternative which will allow a Korean firm to keep certain aspects of its original brand. Fully relying on the brand of a global medical device company can be another good option as this choice will help a specific deal to target a bigger revenue backed by both the reliability and awareness of the MNC brand. This strategy of leveraging the MNC brand can be a practical choice for a medical device firm in a catching-up status.

Third, the policy makers in relation to the Korean medical device industry should build a systematic funding program for medical device companies' overseas market expansion with a focus on the support for later funding stages. Based on the results of the study, medical device firms are asked to be prepared for overseas quality certificates and regulatory approvals for major markets, and all these require significant investment. As potential global partners generally prefer a medical device firm in a more mature funding stage, it is important for medical device firms to secure large amount of funds until they get an access to minority equity investment. The government is already providing companies with early-stage funding programs such as the Tech Incubator Program for Start-ups (here- 
after, TIPS), so it is necessary to develop a support program which could allow a medical device firm to get a stable access to bridge funding for Series B or Series C.

When a potential partnership with a global medical device company is known as an effective measure for entries into larger markets, the findings from this study will be able to guide through the Korean medical device companies. Though this study contributes to the integrated understanding of how Korean medical device companies can partner with global medical device companies, it has some limitations which represent avenues for future study. First, while this research made sure to recruit experienced interviewees from multiple countries such as the US, China, Japan, and Korea, it did not include an interviewee from a European country due to the lack of candidates. As the result points out the importance of the EU market, a representative of a European country would add a meaningful statistic value. Second, to derive more general feedbacks from the interviewees, this research did not specify a target product for a global partnership. Though the general setting was helpful in deriving more structured inputs, some interviewees mentioned that a more customized feedback could be offered if a product type is set. Third, it will be possible to study the stakeholder relationship in the value chain of the medical device industry by utilizing the actor-network theory. The complementation of these limitations in a future study may lay a good foundation for a partnership between catching-up medical device companies and global medical device companies.

Author Contributions: Conceptualization, D.K., K.S. and K.-S.L.; methodology, K.S., G.H.R. and K.-S.L.; validation, K.S. and G.H.R.; formal analysis, D.K.; investigation, D.K.; resources, K.S.; data curation, D.K.; writing-original draft preparation, D.K.; writing-review and editing, K.S. and K.-S.L.; supervision, K.S.; project administration, K.S. and K.-S.L. All authors have read and agreed to the published version of the manuscript.

Funding: This work was supported by the Medical Device Technology Development Program (20014701, Modular quantitative aging assessment and care service based on multiple sensors for aging in-home) funded by the Ministry of Trade, Industry and Energy (MOTIE, Korea).

Institutional Review Board Statement: Not applicable.

Informed Consent Statement: Not applicable.

Data Availability Statement: The data used in this study are available to other authors who require access to this material.

Conflicts of Interest: The authors declare no conflict of interest.

\section{References}

1. West, J.; Salter, A.; Vanhaverbeke, W.; Chesbrough, H. Open innovation: The next decade. Res. Policy 2014, 43, 805-811. [CrossRef]

2. Cassiman, B.; Veugelers, R. In search of complementarity in innovation strategy: Internal R\&D and external knowledge acquisition. Manag. Sci. 2006, 52, 68-82.

3. Yun, J.J.; Mohan, A.V.; Zhao, X. Collectivism, Individualism and Open Innovation: Introduction to the Special Issue on 'Technology, Open Innovation, Markets and Complexity'. Sci. Technol. Soc. 2017, 22, 379-387. [CrossRef]

4. Schuhmacher, A.; Germann, P.G.; Trill, H.; Gassmann, O. Models for open innovation in the pharmaceutical industry. Drug Discov. Today 2013, 18, 1133-1137. [CrossRef] [PubMed]

5. Boston Consulting Group. Keep Calm and Carry on Funding Medtech R\&D. Available online: https://www.bcg.com/ publications / 2020/five-key-reasons-to-fund-research-and-development-in-the-medical-technology-industry (accessed on 30 July 2021).

6. Chatterji, A.K.; Fabrizio, K.R. Does the market for ideas influence the rate and direction of innovative activity? Evidence from the medical device industry. Strateg. Manag. J. 2016, 37, 447-465. [CrossRef]

7. Batterink, M. Profiting from External Knowledge: How Firms Use Different Knowledge Acquisition Strategies to Improve Their Innovation Performance; Wageningen University and Research: Wageningen, The Netherlands, 2009.

8. Eisenhardt, K.M.; Martin, J.A. Dynamic capabilities: What are they? Strateg. Manag. J. 2000, 21, 1105-1121. [CrossRef]

9. Maresova, P.; Hajek, L.; Krejcar, O.; Storek, M.; Kuca, K. New regulations on medical devices in Europe: Are they an opportunity for growth? Adm. Sci. 2020, 10, 16. [CrossRef]

10. Enkel, E.; Gassmann, O.; Chesbrough, H. Open R\&D and open innovation: Exploring the phenomenon. RED Manag. 2009, 39, 311-316. 
11. Lichtenthaler, U.; Lichtenthaler, E. Technology transfer across organizational boundaries: Absorptive capacity and desorptive capacity. Calif. Manag. Rev. 2010, 53, 154-170. [CrossRef]

12. Lichtenthaler, U. Open innovation in practice: An analysis of strategic approaches to technology transactions. IEEE Trans. Eng. Manag. 2008, 55, 148-157. [CrossRef]

13. Chesbrough, H.W. The era of open innovation. Manag. Innov. Chang. 2006, 127, 34-41.

14. Henkel, J.; Schöberl, S.; Alexy, O. The emergence of openness: How and why firms adopt selective revealing in open innovation. Res. Policy 2014, 43, 879-890. [CrossRef]

15. Lichtenthaler, U.; Lichtenthaler, E. A capability-based framework for open innovation: Complementing absorptive capacity. J. Manag. Stud. 2009, 46, 1315-1338. [CrossRef]

16. Lee, Y.; Fong, E.; Barney, J.B.; Hawk, A. Why do experts solve complex problems using open innovation? Evidence from the US pharmaceutical industry. Calif. Manag. Rev. 2019, 62, 144-166. [CrossRef]

17. Chesbrough, H.; Chen, E.L. Using inside-out open innovation to recover abandoned pharmaceutical compounds. J. Innov. Manag. 2015, 3, 21-32. [CrossRef]

18. Hung, K.P.; Chou, C. The impact of open innovation on firm performance: The moderating effects of internal R\&D and environmental turbulence. Technovation 2013, 33, 368-380.

19. Lee, M. Strategies for promoting the medical device industry in Korea: An analytical hierarchy process analysis. Int. J. Environ. Res. Public Health 2018, 15, 2659. [CrossRef]

20. Abramovitz, M. Catching up, forging ahead, and falling behind. J. Econ. Hist. 1986, 46, 385-406. [CrossRef]

21. Daigle, B.; Torsekar, M. The EU Medical Device Regulation and the US Medical Device Industry. J. Int. Commer. Econ. 2019, 1, $1-22$.

22. EvaluateMedTech. World Preview 2018, Outlook to 2024. Available online: https:/ / www.evaluate.com/thought-leadership/ medtech/evaluatemedtech-world-preview-2018-outlook-2024 (accessed on 16 July 2021).

23. MedWorld. The World's 10th Largest Medical Device Market. Its Growth Is Mainly Led by IVD (In Vitro Diagnostics). Available online: www.medworld.co.kr/news/articleView.html?idxno=132113 (accessed on 16 July 2021).

24. Chatterji, A.K.; Fabrizio, K.R. Using users: When does external knowledge enhance corporate product innovation? Strateg. Manag. J. 2014, 35, 1427-1445. [CrossRef]

25. Gopalakrishnan, S.; Bierly, P.E. The impact of firm size and age on knowledge strategies during product development: A study of the drug delivery industry. IEEE Trans. Eng. Manag. 2006, 53, 3-16. [CrossRef]

26. Gassmann, O. Opening up the innovation process: Towards an agenda. RED Manag. 2006, 36, $223-228$.

27. Tomaskova, H.; Maresova, P.; Penhaker, M.; Augustynek, M.; Klimova, B.; Fadeyi, O.; Kuca, K. The business process model and notation of open innovation: The process of developing medical instrument. J. Open Innov. Technol. Mark. Complex. $2019,5,101$. [CrossRef]

28. Ray, P.P.; Amaral, J.F.; Hinoul, P. Innovation best practices in the medical device industry. Tech. Vasc. Interv. Radiol. 2017, 20, 90-93. [CrossRef] [PubMed]

29. Lee, H.J.; Bae, E.Y. Eliciting preferences for medical devices in South Korea: A discrete choice experiment. Health Policy 2017, 121, 243-249. [CrossRef]

30. Peter, L.; Hajek, L.; Maresova, P.; Augustynek, M.; Penhaker, M. Medical devices: Regulation, risk classification, and open innovation. J. Open Innov. Technol. Mark. Complex. 2020, 6, 42. [CrossRef]

31. Yun, J.J.; Yigitcanlar, T. Open innovation in value chain for sustainability of firms. Sustainability 2017, 9, 811. [CrossRef]

32. Mishra, S.; Shukla, V.K. Quality management and US regulatory auditing guidelines for medical device manufacturers. Health Technol. 2021, 11, 733-744. [CrossRef]

33. Lee, M.; Yoon, K. Ecosystem of the medical device industry in South Korea: A Network Analysis Approach. Health Policy Technol. 2018, 7, 397-408. [CrossRef]

34. Lee, M.; Yoon, K.; Lee, K.S. Social network analysis in the legislative process in the Korean medical device industry. Inq. J. Health Care Organ. Provis. Financ. 2018, 55, 0046958018791858. [CrossRef]

35. Gulati, R. Network location and learning: The influence of network resources and firm capabilities on alliance formation. Strateg. Manag. J. 1999, 20, 397-420. [CrossRef]

36. Yun, J.J.; Zhao, X.; Hahm, S.D. Harnessing the value of open innovation: Change in the moderating role of absorptive capability. Knowl. Manag. Res. Pract. 2018, 16, 305-314. [CrossRef]

37. Rogers, M.J.; Maranas, C.D.; Ding, M. Valuation and design of pharmaceutical R\&D licensing deals. AIChE J. 2005, 51, 198-209.

38. Mathews, J.A. A resource-based view of Schumpeterian economic dynamics. J. Evol. Econ. 2002, 12, 29-54. [CrossRef]

39. Priem, R.L.; Butler, J.E. Is the resource-based "view" a useful perspective for strategic management research? Acad. Manag. Rev. 2001, 26, 22-40.

40. Cohen, W.M.; Levinthal, D.A. Absorptive capacity: A new perspective on learning and innovation. Adm. Sci. Q. 1990, 35, 128-152. [CrossRef]

41. Lane, P.J.; Koka, B.R.; Pathak, S. The reification of absorptive capacity: A critical review and rejuvenation of the construct. Acad. Manag. Rev. 2006, 31, 833-863. [CrossRef]

42. Aquilani, B.; Abbate, T.; Codini, A. Overcoming cultural barriers in open innovation processes through intermediaries: A theoretical framework. Knowl. Manag. Res. Pract. 2017, 15, 447-459. [CrossRef] 
43. Deloitte. The Next Wave of Innovation. Available online: https://www2.deloitte.com/us/en/insights/industry/life-sciences/ medtech-research-and-development-innovation.html (accessed on 20 July 2021).

44. Shin, K.; Kim, E.; Jeong, E. Structural relationship and influence between open innovation capacities and performances. Sustainability 2018, 10, 2787. [CrossRef]

45. Dubickis, M.; Gaile-Sarkane, E. Factors Influencing Technology Transfer in Companies at Emerging Economies. Sci. Technol. Soc. 2021, 26, 242-271. [CrossRef]

46. Chatterji, D. Accessing external sources of technology. Res. Technol. Manag. 1996, 39, 48-56. [CrossRef]

47. Kirkire, M.S.; Rane, S.B. Evaluation of success factors for medical device development using grey DEMATEL approach. J. Model. Manag. 2017, 12, 204-223. [CrossRef]

48. U.S. Food and Drug Administration. Medical Device Innovation Initiative White Paper. Available online: https:/ /www.fda.gov/ about-fda/cdrh-innovation/medical-device-innovation-initiative-white-paper (accessed on 21 July 2021).

49. Lee, M.; Yoon, Y.; Ryu, G.H.; Bok, H.S.; Yoon, K.; Park, S.; Lee, K.S. Innovative distribution priorities for the medical devices industry in the fourth industrial revolution. Int. Neurourol. J. 2018, 22, S83. [CrossRef]

50. Pietzsch, J.B.; Shluzas, L.A.; Paté-Cornell, M.E.; Yock, P.G.; Linehan, J.H. Stage-gate process for the development of medical devices. J. Med. Devices 2009, 3, 021004. [CrossRef]

51. MFDS (Ministry of Food and Drug Safety). Guidance on GMP (Good Manufacturing Practices) for Medicinal Products. Available online: https: / / www.mfds.go.kr/brd/m_1060/view.do?seq=14852 (accessed on 2 August 2021).

52. Linders, P.W. Setting Standards: ISO 13485: Challenges in Achieving High-Level Structure Compliance. Biomed. Instrum. Technol. 2020, 54, 68-70. [CrossRef]

53. Kintzlinger, M.; Nissim, N. Keep an eye on your personal belongings! The security of personal medical devices and their ecosystems. J. Biomed. Inform. 2019, 95, 103233. [CrossRef] [PubMed]

54. Lee, M.; Park, S.; Lee, K.S. What are the features of successful medical device start-ups? Evidence from Korea. Sustainability 2019, 11, 1948. [CrossRef]

55. Kim, B.; Kim, H.; Jeon, Y. Critical success factors of a design startup business. Sustainability 2018, 10, 2981. [CrossRef]

56. Croce, A.; Guerini, M.; Ughetto, E. Angel financing and the performance of high-tech start-ups. J. Small Bus. Manag. 2018, 56, 208-228. [CrossRef]

57. Davis, L. Intellectual property rights, strategy and policy. Econ. Innov. New Technol. 2004, 13, 399-415. [CrossRef]

58. Medina, L.A.; Kremer, G.E.O.; Wysk, R.A. Supporting medical device development: A standard product design process model. J. Eng. Des. 2013, 24, 83-119. [CrossRef]

59. Damanpour, F.; Gopalakrishnan, S. The dynamics of the adoption of product and process innovations in organizations. J. Manag. Stud. 2001, 38, 45-65. [CrossRef]

60. Lin, C.H.; Jang, S.L. The impact of M\&As on company innovation: Evidence from the US medical device industry. Scientometrics 2010, 841, 119-131.

61. Kim, D.S.; Lee, J.S.; Cho, S.H.; Kim, M.S.; Kim, N.H. An Analysis of the Patent Trend of Korean Medical Equipment Manufacturers: 98 companies holding domestic registered patents through R\&D. J. Bus. Econ. 2018, 34, 165-187.

62. Slate, W.B. Filing Strategies under the patent cooperation treaty. Intellect. Prop. Technol. Law J. 2002, 14, 1.

63. Alexy, O.; Criscuolo, P.; Salter, A. Does IP strategy have to cripple open innovation? MIT Sloan Manag. Rev. 2009, 51, 71.

64. Veugelers, R.; Cassiman, B. Make and buy in innovation strategies: Evidence from Belgian manufacturing firms. Res. Policy 1999, 281, 63-80. [CrossRef]

65. Kim, E.; Lee, I.; Kim, H.; Shin, K. Factors Affecting Outbound Open Innovation Performance in Bio-Pharmaceutical Industry-Focus on Out-Licensing Deals. Sustainability 2021, 13, 4122. [CrossRef]

66. Kim, Y.H.; Schoenherr, T. The effects of supply chain integration on the cost efficiency of contract manufacturing. J. Supply Chain Manag. 2018, 54, 42-64. [CrossRef]

67. Lichtenthaler, U. External commercialization of knowledge: Review and research agenda. Int. J. Manag. Rev. 2005, 7, 231-255. [CrossRef]

68. Pisano, G.P. The R\&D Boundaries of the Firm: An Empirical Analysis. Adm. Sci. Q. 1990, 35, $153-176$.

69. Yun, J.J.; Won, D.; Park, K. Dynamics from open innovation to evolutionary change. J. Open Innov. Technol. Mark. Complex. 2016, 2, 7. [CrossRef]

70. Anand, B.N.; Khanna, T. The structure of licensing contracts. J. Ind. Econ. 2000, 48, 103-135. [CrossRef]

71. Winterhalter, S.; Zeschky, M.B.; Neumann, L.; Gassmann, O. Business models for frugal innovation in emerging markets: The case of the medical device and laboratory equipment industry. Technovation 2017, 66, 3-13. [CrossRef]

72. Lee, G.W.; Kim, S.B.; Kim, Y.B.; Kim, D.Y. Study on Factors Influencing Purchase Intention of Medical Device-Focusing on ENT Unit. Korean J. Health Serv. Manag. 2011, 5, 125-132. [CrossRef]

73. Chatterji, A.K. Spawned with a silver spoon? Entrepreneurial performance and innovation in the medical device industry. Strateg. Manag. J. 2009, 30, 185-206. [CrossRef]

74. Jeong, H.; Shin, K.; Kim, E.; Kim, S. Does open innovation enhance a large firm's financial sustainability? A case of the Korean food industry. J. Open Innov. Technol. Mark. Complex. 2020, 6, 101. [CrossRef]

75. Chen, G.; Kang, J.K.; Kim, J.M.; Na, H.S. Sources of value gains in minority equity investments by private equity funds: Evidence from block share acquisitions. J. Corp. Financ. 2014, 29, 449-474. [CrossRef] 
76. Saaty, T.L. How to make a decision: The analytic hierarchy process. Eur. J. Oper. Res. 1990, 48, 9-26. [CrossRef]

77. Medina, L.A.; Dávila, S.; Okudan Kremer, G.E.; Wysk, R.A. Design for FDA: A Predictive Model for the FDA's Decision Time for Medical Devices. In Proceedings of the International Design Engineering Technical Conferences and Computers and Information in Engineering Conference, Chicago, IL, USA, 12-15 August 2012; p. V004T05A021.

78. Yun, J.J.; Won, D.; Park, K.; Jeong, E.; Zhao, X. The role of a business model in market growth: The difference between the converted industry and the emerging industry. Technol. Forecast. Soc. Chang. 2019, 146, 534-562. [CrossRef]

79. Gassmann, O.; Daiber, M.; Enkel, E. The role of intermediaries in cross-industry innovation processes. RED Manag. 2011, 41, 457-469.

80. Cwalina, T.B.; Jella, T.K.; Acuña, A.J.; Samuel, L.T.; Kamath, A.F. Venture Capital Investment in Orthopaedics: Has the Landscape Changed over the Past Two Decades (2000-2019)? Surg. Innov. 2021, 15533506211031072. [CrossRef]

81. Kampfrath, T.; Cotten, S.W. The new collaborative path in medical device development: The medical device innovation consortium. Clin. Biochem. 2013, 46, 1320-1322. [CrossRef] [PubMed]

82. Kramer, D.B.; Tan, Y.T.; Sato, C.; Kesselheim, A.S. Ensuring medical device effectiveness and safety: A cross-national comparison of approaches to regulation. Food Drug Law J. 2014, 69, 1. [PubMed]

83. Ahuja, G.; Katila, R. Technological acquisitions and the innovation performance of acquiring firms: A longitudinal study. Strateg. Manag. J. 2001, 22, 197-220. [CrossRef] 